\title{
The pluses and minuses of bariatric surgery for morbid obesity: An endocrinological perspective
}

\author{
Antonis Polymeris
}

Second Department of Endocrinology, Alexandra General Hospital, Athens, Greece

\begin{abstract}
Obesity both in adults and children has emerged as a worldwide epidemic. Obesity is associated with an increased risk of a number of comorbidities including type 2 diabetes mellitus, hypertension, dyslipidemia, obstructive sleep apnea, certain types of cancer, degenerative joint disease, non-alcoholic fatty liver disease, reflux esophagitis, stroke, coronary heart disease, venous stasis ulcers, cholelithiasis, erectile dysfunction and polycystic ovary syndrome. It is now generally accepted that bariatric surgery procedures induce long-term weight loss and offer resolution or dramatic improvement in numerous comorbidities of obesity, including type 2 diabetes mellitus, hypertension and dyslipidemia. These effects mainly arise from endocrine changes resulting from the gastrointestinal surgical procedures. The aim of this short review was to evaluate the pros and cons of bariatric surgery for morbid obesity seen from the perspective of a practicing endocrinologist.
\end{abstract}

Key words: Bariatric surgery, Hypertension, Obesity comorbidities, Type 2 diabetes mellitus

\section{INTRODUCTION}

Hippocrates of the Greek island of Kos was the first in the West to state, in $410 \mathrm{BC}$, that "obese people die early". It is now well established that, indeed, obesity augments both morbidity and mortality and it can be used as an independent risk factor for premature mortality. ${ }^{1-3}$ In the present day, however, obesity has developed into an epidemic of global proportions in adults and children alike and is moreover associated with enhanced risk of multiple comorbidities including type 2 diabetes mellitus, hypertension, dyslipidemia, obstructive sleep apnea, certain types

Address for correspondence:

Antonis Polymeris, e-mail: antonispolymeris@gmail.com

Received 13-05-12, Revised 03-07-12, Accepted 28-07-12 of cancer, degenerative joint disease, non-alcoholic fatty liver disease, reflux esophagitis, stroke, coronary heart disease, venous stasis ulcers, cholelithiasis, erectile dysfunction and polycystic ovary syndrome. ${ }^{4,5}$ In patients with a very high body mass index (BMI) and in morbidly obese, low calorie diets, lifestyle and behavioral modification, exercise programs and pharmacotherapy in various combinations usually have poor and transient results. ${ }^{6}$ In these cases, bariatric surgery may be the only available effective option for long-term weight loss and for an improvement of metabolic abnormalities such as type 2 diabetes, dyslipidemia and hypertension. ${ }^{7}$ The beneficial effects of bariatric surgery are not only dependent on weight loss but also on the endocrine consequences of the gastrointestinal surgical procedure. ${ }^{8,9}$ It should be noted 
here that even a moderate reduction of body weight may improve insulin sensitivity and the metabolic profile of obese patients with diabetes, impaired glucose tolerance or impaired fasting glucose. Furthermore, there is an improvement of hypertension and of the lipid profile. ${ }^{10-12}$ Indeed, long-term weight reduction may result in a decrease in overall mortality. ${ }^{13}$ In this review, the pros and cons of bariatric surgery in relation to its effectiveness and complications will be evaluated from an endocrinological perspective. Proposed criteria for submission to bariatric surgery are provided.

\section{CURRENT GUIDELINES FOR PATIENT SELECTION FOR BARIATRIC SURGERY ${ }^{14}$}

- BMI $>40 \mathrm{~kg} / \mathrm{m}^{2}$ or BMI $35-40 \mathrm{~kg} / \mathrm{m}^{2}$ with significant comorbidities (type 2 diabetes, hypertension, sleep apnea, hyperlipidemia)

- Acceptable operational risk

- Documented failure of non-surgical weight loss programs

- Psychologically stable patient with realistic expectations

- Well informed and motivated patient

- Supportive family and social environment

- Absence of uncontrolled psychotic or depressive disorder

- No active alcohol or substance abuse

(National Institutes of Health Consensus 1991, National Heart, Lung and Blood Institute Guidelines 1998).

\section{NON-SURGICAL APPROACH IN TREATING OBESITY}

Conventional treatment of high BMI or morbid obesity (caloric restriction, pharmacologic, lifestyle modification, behavioral) usually results in short-term weight loss of approximately 5-10\% body weight and, according to several published studies, up to $18.8 \%$ within twelve months. ${ }^{15,16}$ Surgical procedures result in weight loss between 50-75\% of excess body weight or $20-40 \mathrm{~kg}$ of initial body weight and a reduction in
BMI of $10-15 \mathrm{~kg} / \mathrm{m}^{2} .^{17,18}$ Weight loss can be sustained for more or less up to 16 years after surgical procedures compared with the typical weight regain within 6-24 months following conventional treatment. ${ }^{16,19-21}$

\section{COMMON TYPES OF BARIATRIC SURGERY}

Bariatric surgical procedures are divided into three groups: restrictive, malabsorptive and mixed. ${ }^{22}$ Restrictive procedures reduce the size of the stomach resulting in early satiety and decreased caloric intake. Currently, the most frequently performed restrictive procedures are vertical banded gastroplasty, sleeve gastrectomy and laparoscopic adjustable gastric banding. ${ }^{7}$ Malabsorptive procedures decrease the functional length of the small intestine leading to diminished nutrient absorption. ${ }^{23,24}$ Both techniques are applied simultaneously in mixed procedures. Roux-en-Y and biliopancreatic diversion with duodenal switch have both restrictive and malabsorptive aspects and they are the most effective ${ }^{22,24}$ (Figure 1).

\section{BENEFICIAL EFFECT ON WEIGHT}

The mean percentage excess weight loss two years after bariatric surgery, according to a meta-analysis, was $61.2 \%$ for all procedures (range: $47.5 \%$ for gastric band to $70.1 \%$ for biliopancreatic diversion with duodenal switch). ${ }^{17}$ Surgical patients appear to decrease their initial body weight from 20 to $30 \mathrm{~kg}$, which is maintained for up to 10 years following bariatric surgery. ${ }^{25}$ In a study of 1035 surgical patients, the mean initial excess weight loss was $67.1 \%$ and was

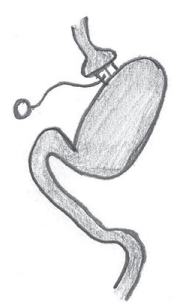

Adjustable

Gastric Band (AGB)

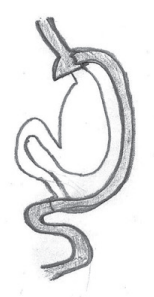

Roux-en-Y

Gastric Bypass (RYGB)

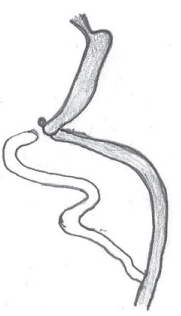

Biliopancreatic Diversion with a Duodenal Switch (BPD-DS)

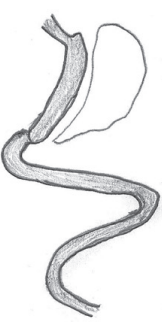

Vertical Sleeve Gastrectomy (VSG)
Figure 1. Most common bariatric surgical procedures. 
maintained for up to 16 years. ${ }^{19}$ One to two years after bariatric surgery procedure (mainly vertical banded gastroplasty and Roux-en-Y gastric bypass), the mean weight loss is maximal, then slowly increases until year $8-10$, and thereafter body weight stabilizes. ${ }^{13}$

\section{BENEFICIAL EFFECTS ON MEDICAL CO MORBIDITIES}

\section{Beneficial effects of bariatric surgery on diabetes and dyslipidemias}

In a meta-analysis of 136 studies and 22,094 patients, diabetes was completely resolved in $76.8 \%$ and resolved or improved in $86.0 \%$ of the patients. Diabetes mellitus resolution was $48 \%$ after laparoscopic gastric banding, $68 \%$ after vertical banded gastroplasty, $84 \%$ after Roux-en-Y and $98 \%$ after biliopancreatic diversion. ${ }^{17}$ In another large metaanalysis (621 studies, 135,246 patients), $78.1 \%$ of obese diabetics had complete diabetes resolution after a bariatric surgical procedure and $86.6 \%$ showed improvement of the disease. Additionally, $95.1 \%$ of patients had diabetes resolution after biliopancreatic diversion with duodenal switch, $80.3 \%$ after gastric bypass, $79.7 \%$ after gastroplasty and $56.7 \%$ after laparoscopic adjustable gastric banding. ${ }^{26}$ Gastrointestinal surgery appears to offer a novel endpoint: complete diabetes remission..$^{27-29}$ Roux-en-Y gastric bypass and a variant of biliopancreatic diversion in 26 and 111 patients with morbid obesity, respectively, was followed by resolution of diabetes in $89 \%$ and $99 \%$ of the patients up to two years after surgery, respectively. ${ }^{30}$ Interestingly, euglycemia and normal insulin levels occur within days after surgery, long before there is any significant weight loss. ${ }^{31,32}$ The mechanisms of action of bariatric surgery procedures are the result of endocrine and neural signals that affect appetite and satiety as well as a result of a complex interaction of malabsorption and gastric restriction. All bariatric procedures improve glucose homeostasis, with gastric bypass and biliopancreatic diversion being the fastest and most effective. There are two main hypotheses to explain the acute increase in insulin sensitivity following this type of operations, the Upper and the Lower Intestinal Hypothesis..$^{33}$ According to the first, gastric bypass results in reduced secretion of factors such as ghrelin (an orexigenic hormone) and anti-incretins that decrease insulin release and/or increase insulin resistance. According to the Lower Intestinal Hypothesis, the rapid nutrient delivery to the lower intestine stimulates the L cells resulting in increased secretion of incretins (such as the anorexigenic hormones: peptide YY and glucagon like peptide 1 - GLP1) that enhances the insulin secretion and/or action..$^{33}$ Besides these endocrine changes, neural impulses transmitted through vagal pathways may influence eating behavior, resulting in weight loss and improvement of glucose homeostasis. ${ }^{34}$ Therefore, the question that arises is whether type 2 diabetes is an operable disease, despite the fact that after vertical banded gastroplasty or Roux-enY gastric bypass, only $36 \%$ of prior diabetic patients remained free of the disorder at 10 years. ${ }^{29}$ In recent IDF recommendations for the management of type 2 diabetes, bariatric surgery is considered as an appropriate treatment for type 2 obese diabetics (BMI $\geq 35 \mathrm{~kg} / \mathrm{m}^{2}$ ) not achieving recommended targets (with medical treatment). Also, mildly obese diabetics (BMI $30-35 \mathrm{~kg} / \mathrm{m}^{2}$ ) under some circumstances should be eligible for bariatric surgery. ${ }^{35}$

Lipid profile improved in over $70 \%$ of patients following bariatric surgery. ${ }^{17}$ Total cholesterol, low density lipoprotein and triglycerides decreased, while high density lipoprotein showed no significant change. ${ }^{17}$ The prospective controlled SOS study showed that patients two and ten years after bariatric surgery exhibited an improvement in hypertriglyceridemia and an increase of high density lipoprotein. ${ }^{29}$

\section{Beneficial effects of bariatric surgery on hypertension}

The prevalence of hypertension is reduced after bariatric surgery and it appears that $79 \%$ of hypertensive obese patients experience improvement or resolution of hypertension. ${ }^{17}$ Improvement of hypertension has also been reported in non severely obese patients with $\mathrm{BMI}<35 \mathrm{~kg} / \mathrm{m}^{2}$. ${ }^{36}$

\section{Beneficial effects of bariatric surgery on obstructive sleep apnea}

Another benefit of bariatric surgery is that it reduces the prevalence of obstructive sleep apnea, as $86 \%$ of the patients with this comorbidity recovered. ${ }^{17,37}$ Some studies showed complete resolution of 
sleep apnea for patients with a respiratory disturbance index (RDI) $<40$ or improvement for patients with $\mathrm{RDI}>40 .{ }^{38}$

\section{Beneficial effects of bariatric surgery on of cardiac function}

Weight loss after bariatric surgery results in decrease of left ventricular wall thickness, increase in left ventricular ejection fraction and improvement in overall cardiac function..$^{39}$ Weight loss appears to correlate with the right ventricular end-diastolic area and the right ventricular systolic pressure. ${ }^{40}$

\section{Beneficial effects of bariatric surgery on gastroesophageal reflux disease}

The improvement seen in gastroesophageal reflux after bariatric surgery may be a result of the decrease in intra-abdominal pressure. ${ }^{41}$

\section{Beneficial effect of bariatric surgery on non-alcoholic fatty liver disease}

Bariatric surgery is associated with non-alcoholic fatty liver disease improvement in most morbidly obese patients. ${ }^{42}$

\section{Beneficial effects of bariatric surgery on the reproductive system}

In Females: Obese females often suffer from infertility and polycystic ovary syndrome which is associated with insulin resistance and hyperinsulinemia. Weight loss after bariatric surgery results in decreased hyperandrogenemia and restoration of menstrual cyclicity and fertility. ${ }^{43,44}$

In Males: Obesity is related to abnormalities in the pituitary-gonadal axis and hypoandrogenism in men, probably due to aromatization of testosterone to estrogen in peripheral adipose tissue. Obese men also experience erectile dysfunction. Weight loss after bariatric surgery results in significant improvement in all these abnormalities. ${ }^{45}$

\section{Beneficial effects of bariatric surgery on venous disease}

Obese patients usually have various degrees of venous stasis (chronic venous insufficiency), leg ulcers, superficial thrombophlebitis and deep vein thrombosis. Surgically induced weight loss improves all these comorbidities. ${ }^{46}$

\section{Beneficial effects of bariatric surgery on pseudotumor cerebri}

Severe obesity, especially in women, may be associated with intracranial hypertension, also known as pseudotumor cerebri, which is attributable to increased intra-abdominal pressure. Weight loss after bariatric surgery decreases cerebrospinal pressure and relieves symptoms such as headache and tinnitus. ${ }^{47}$

\section{Beneficial effects of bariatric surgery on urinary incontinence}

Many women with severe obesity experience urinary incontinence due to increased intra-abdominal and bladder pressure. Surgically induced weight loss resolves this problem almost uniformly. ${ }^{48}$

\section{Beneficial effects of bariatric surgery on degenerative joint disease}

Severe obesity is accompanied by musculoskeletal and lower back pain and leads to degenerative joint disease. Weight reduction after bariatric surgery results in pain relief and decreases the need for orthopedic surgery. ${ }^{49}$

\section{Beneficial effects of bariatric surgery on chronic kidney disease}

It is well known that morbid obesity is associated an increased risk for the development of end stage chronic kidney disease. There is evidence that surgically induced weight loss reduces the risk of chronic kidney disease progression. ${ }^{50}$

\section{Beneficial effects of bariatric surgery on the quality of life}

Bariatric surgery patients experience an improvement in quality of life and psychosocial functioning after weight loss. ${ }^{51,52}$

\section{Safety and mortality of bariatric surgery}

Mortality rates after bariatric surgical procedures appear to be equivalent with those of minimal abdominal surgeries such as laparoscopic cholecystectomy $(0.3-0.6 \%) .{ }^{53}$ The mortality rate in many bariatric surgery cohorts is very low. ${ }^{13}$ In one study, the mortality rate was $0.68 \%$ in the surgery group compared with $6.17 \%$ in control subjects, which translates to an impressive $89 \%$ reduction in the relative risk of death. ${ }^{19}$ The early overall mortality after bariatric surgery in 
a meta-analysis was $0.28 \%$ and increased to $0.35 \%$ between 30 days and two years after surgery. ${ }^{54}$ Mortality rises in patients aged over 60 with preexisting cardiopathies.$^{55}$ Generally, bariatric surgery reduces long-term mortality in operated patients compared to conventionally treated patients. In a recent metaanalysis from 8 trials $(14,052$ operated patients and 29,970 controls), gastric banding and gastric by-pass were associated with a reduced risk of global mortality $(\mathrm{OR}=0.55$, CI $0.49-0.63)$, of cardiovascular mortality $(\mathrm{OR}=0.58$, CI $0.46-0.73)$ and of all cause mortality $(\mathrm{OR}=0.70$, CI $0.59-0.84) .{ }^{56}$

\section{Cost-effectiveness of bariatric surgery}

Bariatric surgical procedures appear to be costeffective compared with non-surgical interventions. Further research is required in order to clarify the long-term cost-effectiveness. ${ }^{57}$

\section{Detrimental effects of bariatric surgery on micronutrients}

Anemia due to iron, folic acid and vitamins B12 and $\mathrm{C}$ deficiencies is a side effect of bariatric surgery procedures, especially of the restrictive type. ${ }^{58}$ Iron deficiency is very common after gastric bypass. Vitamin $\mathrm{D}$ and calcium deficiency and subsequent secondary hyperparathyroidism lead to overt bone loss and osteoporosis. ${ }^{59}$ Deficiencies of vitamin B12, thiamin or copper result in peripheral neuropathy and also in central nervous system deficits. Furthermore, lack of thiamine results in Wernicke's encephalopathy. ${ }^{60}$ Bariatric surgery incorporating restrictive or mixed procedures is usually associated with vitamin $\mathrm{K}$ and $\mathrm{A}$ and zinc and selenium depletion. ${ }^{61}$ All these deficiencies result in numerous pathologies such as: mixed sensorimotor disturbances (copper), night blindness (niacin), coagulopathy (vitamin K), rash (vitamin E), edema and alopecia (protein malnutrition), pellagra (niacin), acrodermatitis (zinc) and cardiomyopathy (selenium and thiamin). ${ }^{22,62}$ Therefore, there is a need for lifelong substitution therapy and follow-up. In order to avoid or to minimize nutritional complications and to prevent weight regain, all patients "should receive care from a multidisciplinary team including an experienced primary care physician, endocrinologist or gastroenterologist and consider enrolling postoperatively in a comprehensive program for nutrition and lifestyle management" ${ }^{63,64}$ A small number of patients $(0.2 \%)$ after gastric bypass surgery experience hypoglycemia as a result of increased GLP1 levels or gastric dumping. ${ }^{65}$

\section{Other detrimental effects of bariatric surgery}

Drug malabsorption is another potential problem after bariatric surgery ${ }^{66}$ Renal stones due to oxalosis and liver failure are serious postoperative complications. ${ }^{65}$ Many patients after surgically induced weight loss experience significant skin excess, laxity and ptosis leading to a large number of unpleasant consequences including hygienic, dermatologic and cosmetic impairments, the latter requiring expensive cosmetic surgical procedures including abdominoplasty. ${ }^{67}$

\section{Detrimental effects of bariatric surgery on behavior}

Some patients after bariatric surgery experience binge and night eating and depression. ${ }^{68,69}$ Some studies have shown an increased mortality rate due to accidents and suicides after bariatric surgery. ${ }^{69-71}$

\section{Postoperative complications of bariatric surgery}

In the immediate postoperative period, venous thromboembolism and sepsis, as well as anastomotic leaks at the site of gastrojejunostomy, are the most serious complications..$^{24}$ The incidence of venous thromboembolism is from 0.4 to $3.1 \%$ and the incidence of anastomotic leaks is $0.5-3 \% .{ }^{24}$ Increased heart rate and respiratory distress are the most common symptoms of anastomotic leaks. Other short-term postoperative complications are bleeding, infections, small bowel obstruction and hernias. ${ }^{24}$

Long-term surgical complications include dumping syndrome, nausea and vomiting (especially after vertical banded gastroplasty), ulcers, gastritis and erosions (especially after laparoscopic adjustable gastric banding), adhesions, bile reflux, gallstones, diarrhea, band erosion, slippage and dilatation. ${ }^{24,62}$

In conclusion: It is now generally accepted that bariatric surgery is the most effective procedure for long-term weight loss among the morbidly obese. Additionally, bariatric surgery offers an improvement in metabolic abnormalities such as type 2 diabetes, dyslipidemia and hypertension. These beneficial effects stem not only from weight loss but also from endocrine changes resulting from the gastrointestinal 
surgical procedures. In summary, bariatric surgery is associated with decreased overall mortality. All these favorable effects of bariatric surgery are closely related to judicious selection of patients who are candidates for surgery, to the efficiency of the surgical group and to good postoperative management of the patients.

\section{REFERENCES}

1. Sjostrom LV, 1992 Mortality of severely obese subjects. Am J Clin Nutr 55: Suppl: 516-523.

2. Peeters A, Barendregt JJ, Willekens F, Mackenbach JP, Al Mamun A, Bonneaux L, 2003 Obesity in adulthood and its consequences for life expectancy: A life table analysis. Ann Intern Med 138: 24-32.

3. Calle EE, Thun MJ, Petrelli JM, 1999 Body-mass index and mortality in a prospective cohort of US adults. N Engl J Med 341: 1097-1105.

4. Ogden CL, Carroll MD, Curtin LR, McDowell MA, Tabak CJ, Flegal KM, 2006 Prevalence of overweight and obesity in the United States. JAMA 295: 1549-1555.

5. Haslam DW, James WPT, 2005 Obesity. Lancet 366: 1197-1209.

6. Anderson JW, Grant L, Gotthelf L, Stifler LT, 2006 Weight loss and long term follow-up of severely obese individuals treated with an intense behavioral program. Int J Obes 31: 488-493.

7. Santry HP, Gillen DL, Launderdale DS, 2005 Trends in bariatric surgical procedures. J Am Med Assoc 294: 1909-1917.

8. Rubino F, R`bibo S, del Genio F, Mazumbar M, McGraw TE, 2010 Metabolic surgery: the role of the gastrointestinal tract in diabetes mellitus. Nat Rev Endocrinol 6: 102-109.

9. Thaler JP, Cummings DE, 2009 Hormonal and metabolic mechanisms of diabetes remission after gastrointestinal surgery. Endocrinology 150: 2518-2525.

10. Knowler WC, Barrett-Connor E, Fowler SE, et al, 2002 Reduction in the incidence of type 2 diabetes with life style intervention or metformin. N Engl J Med 346: 393-403.

11. Stevens VJ, Obarzanek E, Cook NR, et al, 2001 Long term weight loss and changes in blood pressure results from the trials of hypertension prevention, phase II. Ann Intern Med 134: 1-11.

12. Wood PD, Stefanick ML, Dreon DM, et al, 1988 Changes in plasma lipids and lipoproteins in overweight men during weight loss through dieting as compared with exercise. N Engl J Med 319: 1173-1179.

13. Sjostrom L, Narbro K, Sjostrom CD, et al, 2007 Effects of bariatric surgery on mortality in Swedish obese subjects. N Engl J Med 357: 741-752.

14. National Institutes of Health Consensus Development Conference Statement 1991, 1992 Gastrointestinal surgery for severe obesity. Am J Clin Nutr 52: Suppl
2: 615-619.

15. Safer DJ, 1991 Diet, behavior modification and exercise: a review of obesity treatments from a long term perspective. South Med J 84: 1470-1474.

16. Yanovski SZ, Yanovski JA, 2002 Drug therapy: Obesity. N Engl J Med 346: 591-602.

17. Buchwald H, Avidor Y, Braunwald E, et al, 2004 Bariatric surgery: a systematic review and meta-analysis. JAMA 292: 1724-1737.

18. Maggard MA, Shugarman LR, Suttorp M, et al, 2005 Meta-analysis: surgical treatment of obesity. Ann Intern Med 142: 547-559.

19. Christou NV, Sampalis JS, Liberman M, et al, 2004 Surgery decreases long term mortality, morbidity and health care use in morbidly obese patients. Ann Surg 240: 416-424.

20. Waden TA, Butryn ML, Byrne KJ, 2004 Efficacy of life style modification for long term weight control. Obes Res 12: 151-162.

21. Drenick EJ, Johnson D, 1978 Weight reduction by fasting and semi-starvation in morbid obesity. Int $\mathrm{J}$ Obes 2: 123-132.

22. Elder KA, Wolfe MB, 2007 Bariatric surgery: A Review of procedures and outcomes. Gastroenterology 132: 2253-2271.

23. Schneider BE, Mun EC, 2005 Surgical management of morbid obesity. Diabetes Care 28: 475-480.

24. Bult JFB, van Dalen T, Muller AF, 2008 Surgical treatment of obesity. Eur J Endocrinol 158: 135-145.

25. McTigue KM, Harris R, Hemphill B, et al, 2003 Screening and interventions for obesity in adults: summary of the evidence for the US preventive services task force. Ann Intern Med 139: 933-949.

26. Buchwald H, Estok R, Fahrbach K, et al, 2009 Weight and Type 2 Diabetes after Bariatric Surgery: Systematic Review and Meta-analysis. Am J Med 122: 248-256.

27. Rubino F, Schauer PR, Kaplan LM, Cummings DE, 2010 Metabolic surgery to treat type 2 diabetes: Clinical outcomes and mechanisms of action. Ann Rev Med 61: 393-411.

28. Gill RS, Sharma AM, Gill SS, Birch DW, Karmali S, 2011 The impact of obesity on diabetes mellitus and the role of bariatric surgery. Maturitas 69: 137.

29. Sjostrom L, Lindroos AK, Peltonen M, et al, 2004 Lifestyle, diabetes and cardiovascular risk factors 10 years after bariatric surgery. N Engl J Med 351: 2683-2693.

30. Alexandrides TK, Skroubis G, Kalfarentzos F, 2007 Resolution of diabetes mellitus and metabolic syndrome following Roux-en-Y gastric bypass and a variant of biliopancreatic diversion in patients with morbid obesity. Obes Surg 17: 176-184.

31. Polyzogopoulou EV, Kalfarentzos F, Vagenakis AG, Alexandrides TK, 2003 Restoration of euglycemia and normal acute insulin response to glucose in obese subjects with type 2 diabetes following bariatric surgery. Diabetes 52: 1098-1103.

32. O'Brien PE, 2010 Bariatric surgery: mechanisms, 
indications and outcomes. J Gastroenterol Hepatol 25: 1358-1365.

33. Cummings DE, Overduin J, Foster-Schubert KE, Carlson MJ, 2007 Role of the bypassed proximal intestine in the anti-diabetic effects of bariatric surgery. Surg Obes Relat Dis 3:109-115.

34. Burneo JG, Faught E, Knowlton R, Morawetz R, Kuzniecky R, 2002 Weight loss associated with vagus nerve stimulation. Neurology 59: 463-464.

35. Dixon JB, Zimmet P, Alberti KG, Rubino F, 2011 Bariatric surgery: an IDF statement for obese type 2 diabetes. Diabet Med 28: 628-642.

36. Lee WJ, Wang W, Lee YC, Huang MT, Ser KH, Chen JC, 2008 Effect of laparoscopic mini-gastric bypass for type 2 diabetes mellitus: comparison of BMI $>35 \mathrm{~kg} / \mathrm{m}^{2}$ and $<35 \mathrm{~kg} / \mathrm{m}^{2}$. J Gastrointest Surg 12: 945-952.

37. Grunstein RR, Stenlof K, Hedner JA, Peltonen M, Karason K, Sjostrom L, 2007 Two year reduction in sleep apnea symptoms and associated diabetes incidence after weight loss in severe obesity. Sleep 30: 703-710.

38. Sugerman HJ, Fairman RP, Sood RK, Engle K, Wolfe L, Kellum JM, 1992 Long-term effects of gastric surgery for treating respiratory insufficiency of obesity. Am J Clin Nutr 55: Suppl 2: 597-601.

39. Sugerman HJ, Baron PL, Fairman RP, Evans CR, Vetrovec GW, 1988 Hemodynamic dysfunction in obesity hypoventilation syndrome and the effects of treatment with surgically induced weight loss. Ann Surg 207: 604-613.

40. Garza CA, Pellikka PA, Somers VK, et al, 2010 Structural and functional changes in left and right ventricles after major weight loss following bariatric surgery for morbid obesity. Am J Cardiol 105: 550-556.

41. Lambert DM, Marceau S, Forse RA, 2005 Intra-abdominal pressure in the morbidly obese. Obes Surg 15: 1225-1232.

42. de Freitas AC, Campos AC, Coelho JC, 2008 The impact of bariatric surgery on non alcoholic fatty liver disease. Curr Opin Clin Nutr Metab Care 11: 267-274.

43. Teitelman M, Grotegut CA, Williams NN, Lewis JD, 2006 The impact of bariatric surgery on menstrual patterns. Obes Surg 16: 1457-1463.

44. Gosman GG, King WC, Schrope B, et al, 2010 Reproductive health of women electing bariatric surgery. Fertil Steril 94: 1426-1431.

45. Reis LO, Favaro WJ, Barreiro GC, et al, 2010 Erectile dysfunction and hormonal imbalance in morbidly obese male is reversed after gastric bypass surgery: a prospective randomized controlled trial. Int $\mathrm{J}$ Androl 33: 736-744.

46. Sugerman HJ, Sugerman EL, Wolfe L, Kellum JM Jr, Schweitzer MA, DeMaria EJ, 2001 Risks and benefits of gastric bypass in morbidly obese patients with severe venous stasis disease. Ann Surg 234: 41-46.

47. Chandra V, Dutta S, Albanese CT, Shepard E, FarralesNguyen S, Morton J, 2007 Clinical resolution of severely symptomatic pseudotumor cerebri after gastric bypass in an adolescent. Surg Obes Relat Dis 3: 198-200.

48. Richter HE, Burgio KL, Clements RH, Goode PS, Redden DT, Varner RE, 2005 Urinary and anal incontinence in morbidly obese women considering weight loss surgery. Obstet Gynecol 106: 1272-1277.

49. Serés L, Lopez-Ayerbe J, Coll R, et al, 2006 Increased exercise capacity after surgically induced weight loss in morbid obesity. Obes Res 14: 273-279.

50. Zalesin KC, McCullough PA, 2006 Bariatric surgery for morbid obesity: risks and benefits in chronic kidney disease patients. Adv Chronic Kidney Dis 13: 403-417.

51. Mamplekou E, Komesidou V, Bissias C, Papakonstantinou A, Melissas J, 2005 Psychological condition and quality of life in patients with morbid obesity before and after surgical weight loss. Surg Obes 15: 1177-1184.

52. van Hout GC, Boekestein P, Fortuin FA, Pelle AJ, van Heck GL, 2006 Psychosocial functioning following bariatric surgery. Obes Surg 16: 787-794.

53. Khuri SF, Najjar SF, Daley J, et al, 2001 VA National Surgical Quality Improvement Program. Comparison of surgical outcomes between teaching and non-teaching hospitals in the Department of Veterans Affairs. Ann Surg 234: 370-382.

54. Buchwald H, Estok R, Fahrbach K, Banel D, Sledge I, 2007 Trends in mortality in bariatric surgery: a systematic review and meta analysis. Surgery 142: 621-632.

55. Varela JE, Wilson SE, Nguyen NT, 2006 Outcomes of bariatric surgery in the elderly. Am Surg 72: 865-869.

56. Pontiroli AE, Morabito A, 2011 Long-term prevention of mortality in morbid obesity through bariatric surgery. A systematic review and meta-analysis of trials performed with gastric banding and gastric bypass. Ann Surg 253: 484-487.

57. Picot J, Jones J, Colquitt JL, et al, 2009 The clinical effectiveness and cost- effectiveness of bariatric (weight loss) surgery for obesity: a systematic review and economic evaluation. Health Technol Assess 13: 1-190.

58. Shah M, Simha V, Garg A, 2006 Review: long-term impact of bariatric surgery on body weight, comorbidities, and nutritional status. J Clin Endocrinol Metab 91: 4223-4231.

59. Fleischer J, Stein EM, Bessler M, et al, 2008 The decline in hip bone density after gastric bypass surgery is associated with extent of weight loss. J Clin Endocrinol Metab 93: 3735-3740.

60. Aasheim ET, 2008 Wernicke encephalopathy after bariatric surgery: a systematic review. Ann Surg 248: 714-720.

61. Mechanick JI, Kushner RF, Sugerman HJ, et al, 2008 American Association of Clinical Endocrinologists, The Obesity Society, and American Society for Metabolic \& Bariatric Surgery Medical guidelines for clinical practice for the perioperative nutritional, metabolic, and nonsurgical support of the bariatric surgery patient. Endocr Pract 14: Suppl 1: 1-83. 
62. Pinkney JH, Johnson AB, Gale EA, 2010 The big fat bariatric bandwagon. Diabetologia 53: 1815-1822.

63. Heber D, Greenway FL, Kaplan LM, Livingston E, Salvador J, Still C, 2010 Endocrine and nutritional management of the post-bariatric surgery patient: An Endocrine Society Clinical Practice Guideline. J Clin Endocrinol Metab 95: 4823-4843.

64. Torres AJ, Rubio MA, 2011 The Endocrine Society's Clinical Practice Guideline on endocrine and nutritional management of the post-bariatric surgery patient: Commentary from a European Perspective. Eur J Endocrinol 165: 171-176.

65. Marsk R, Jonas E, Rasmussen F, Näslund E, 2010 Nationwide cohort study of post-gastric bypass hypoglycaemia including 5,040 patients undergoing surgery for obesity in 1986-2006 in Sweden. Diabetologia 53: 2307-2311.

66. Padwal R, Brocks D, Sharma AM, 2010 A systematic review of drug absorption following bariatric surgery and its theoretical implications. Obes Rev 11: 41-50.

67. Bracaglia R, D'Ettorre M, Gentileschi S, Tambasco D, 2011 "Vest Over Pants" Abdominoplasty in postbariatric patients. Aesthetic Plast Surg [Epub ahead of print] PMID: 21695578.

68. Kruseman M, Leimgruber A, Zumbach F, Golay A, 2010 Dietary, weight, and psychological changes among patients with obesity, 8 years after gastric bypass. J Am Diet Assoc 110: 527-534.

69. Marcus MD, Kalarchian MA, Courcoulas AP, 2009 Psychiatric evaluation and follow up of bariatric surgery patients. Am J Psychiatry 166: 285-291.

70. Omalu BI, Ives DG, Buhari AM, et al, 2007 Death rates and causes of death after bariatric surgery for Pennsylvania residents, 1995 to 2004. Arch Surg 142: 923-929.

71. Adams TD, Gress RE, Smith SC, et al, 2007 Long-term mortality after gastric bypass surgery. N Engl J Med 357: 753-761. 